\title{
Foxp3 overexpression decreases sensitivity to chemotherapy in mouse Lewis lung cancer cells
}

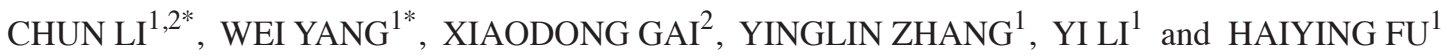 \\ ${ }^{1}$ Department of Immunology, Norman Bethune College of Medicine, Jilin University, Changchun; \\ ${ }^{2}$ Department of Immunology, School of Basic Medical Sciences, Beihua University, Jilin, P.R. China
}

Received May 3, 2012; Accepted August 29, 2012

DOI: $10.3892 / \mathrm{mmr} .2012 .1066$

\begin{abstract}
Chemotherapy is the main strategy for the treatment of lung cancer. However, sensitivity to chemotherapy, one of the main factors affecting the survival rate of patients with lung cancer, is extremely poor. Forkhead box P3 (Foxp3) is the key regulatory gene for the development and function of $\mathrm{CD} 4{ }^{+} \mathrm{CD} 25^{+}$regulatory T cells (Tregs). Increased levels of Tregs and Foxp3 expression in the peripheral blood and tumour specimens of cancer patients are associated with tumour progression and poor prognosis. In addition, certain studies have suggested that Tregs may be resistant to conventional chemotherapy and thus, enhance tumour immune evasion. Previous studies have demonstrated that Foxp3 is also expressed within tumour cells and that it may mimic the function of Tregs. Currently, the correlation between the tumour cell expression of Foxp3 and sensitivity to chemotherapy is unclear. Therefore, it was hypothesised that Foxp3 causes resistance to chemotherapeutic agents in lung cancer cells and that it may consequently promote the progression of lung cancer. In the current study, the expression of Foxp3 in mouse Lewis lung cancer (LLC) cells was detected using RT-PCR and immunocytochemistry. The overexpression of Foxp3, which was accomplished by the transient transfection of recombinant pcDNA3.1-Foxp3 or empty plasmids into LLC cells, was confirmed by RT-PCR and western blot analysis. The inhibition of cell proliferation was measured using MTT assay. The expression of multidrug resistance protein 1 (mdrl) mRNA and its protein product, P-glycoprotein (P-gp), were detected by RT-PCR and flow cytometry, respectively. The results revealed that Foxp3 was expressed by LLC cells. The inhibitory rate of cell proliferation in Foxp3-overexpressing
\end{abstract}

Correspondence to: Dr Haiying Fu or Dr Yi Li, Department of Immunology, Norman Bethune College of Medicine, Jilin University, No. 126 Xinmin Avenue, Changchun, Jilin 130021, P.R. China

E-mail: fuhaiying612@yahoo.com.cn

E-mail: yilili19@yahoo.com.cn

${ }^{*}$ Contributed equally

Key words: forkhead box P3, Lewis lung cancer, adriamycin, mitomycin $\mathrm{C}, \mathrm{P}$-glycoprotein
LLC cells compared with those transfected with an empty plasmid was significantly decreased following adriamycin (ADM) and mitomycin $\mathrm{C}(\mathrm{MMC})$ treatment. The $\mathrm{IC}_{50}$ values of ADM and MMC in Foxp3-overexpressing LLC cells were increased. The expression levels of mdr1 mRNA and P-gp were significantly upregulated in Foxp3 overexpressing LLC cells. These results suggest that Foxp3 reduces the sensitivity of LLC cells to ADM and MMC, thus promoting tumour progression, by upregulating the expression of mdr1 mRNA and P-gp.

\section{Introduction}

Lung cancer is the type of cancer with the highest morbidity and mortality in the world; its 5-year survival rate is less than $16 \%$ (1). Clinical studies have revealed that $80 \%$ of lung cancer cases are non-small cell lung cancer (NSCLC) and that the majority of NSCLC patients are not diagnosed until an advanced stage. Chemotherapy is the main strategy for the treatment of NSCLC. However, the sensitivity to chemotherapy of NSCLC patients is extremely poor, and this is one of the main factors affecting patient survival rate. Therefore, it is important to study the mechanisms of poor sensitivity to chemotherapy to improve the survival rate of patients with lung cancer.

Forkhead box P3 (Foxp3) is a member of the forkhead/winged-helix transcription factor family and is the key regulatory gene and specific molecular marker for the development and function of $\mathrm{CD} 4{ }^{+} \mathrm{CD} 25^{+}$regulatory $\mathrm{T}$ cells (Tregs) (2,3). The function of Tregs in the tumour microenvironment is to inhibit the local immune response, which promotes tumour progression $(4,5)$. In patients with various types of cancer, increased levels of Tregs and Foxp3 expression in peripheral blood and tumour specimens have been associated with poor prognoses (6-9). Foxp3 has previously been reported to be expressed not only in Tregs but also in the tumour cells of patients with pancreatic cancer, melanoma and other types of tumour (10-14). Some of these studies have shown that the expression of Foxp3 within tumour cells is associated with tumour progression and a poor prognosis, suggesting that Foxp3 expression within tumour cells mimics the function of Tregs (12-14). In addition, certain studies have suggested that Tregs are resistant to conventional chemotherapy, thus improving tumour immune evasion $(15,16)$. However, the correlation between the expression of Foxp3 within tumour cells and sensitivity to chemotherapy remains unclear. 
It was hypothesised that Foxp3 expression within lung cancer cells is linked to the resistance to chemotherapeutic agents and the progression of lung cancer. In the current study, after detecting the expression of Foxp3 in mouse Lewis lung cancer (LLC) cells, which are NSCLC cells, the role of Foxp3 in the sensitivity to chemotherapy and the expression of multidrug resistance protein 1 (mdrl) mRNA and its protein product, P-glycoprotein (P-gp), was evaluated after transiently transfecting pcDNA3.1-Foxp3 recombinant plasmids into LLC cells.

\section{Materials and methods}

Reagents and antibodies. The rat anti-mouse Foxp3 (FJK-16s) monoclonal antibody and the goat anti-rat IgG/HRP antibody were purchased from eBioscience (San Diego, CA, USA). The FuGENE transfection reagent and mitomycin C (MMC) were purchased from Roche (Mannheim, Germany). The rabbit anti-mouse P-gp polyclonal antibody was purchased from Boster Biological Technology Ltd. (Wuhan, China). The goat anti-rabbit FITC labelled IgG was purchased from Zhongshan Goldenbridge Biotechnology (Beijing, China). The Ready-to-Use Immunohistochemistry Hypersensitivity UltraSensitive $^{\text {TM }}$ S-P kit was purchased from Maixin-Bio (Fujian, China). Adriamycin (ADM) was purchased from Hisun Chemical Co., Ltd. (Zhejiang, China).

Cells and culture conditions. The mouse LLC cell line was obtained from the Department of Immunology in the Norman Bethune College of Medicine at Jilin University (Changchun, China) and cultured at $37^{\circ} \mathrm{C}$ with $5 \% \mathrm{CO}_{2}$ in complete DMEM (Gibco-BRL, Carlsbad, CA, USA) containing 10\% FBS (Gibco-BRL).

Immunocytochemical staining. Cells were grown overnight on coverslips in 6-well plates to allow for cell attachment. The cells were then washed 3 times with PBS prior to the addition of ice-cold $80 \%$ ethanol at $4^{\circ} \mathrm{C}$ for $10 \mathrm{~min}$. The cells were subsequently incubated with $5 \mathrm{ml}$ of perforated liquid $(0.1 \%$ saponin) for $20 \mathrm{~min}$ at room temperature (RT). The cells were incubated with rat anti-mouse Foxp3 antibody (dilution 1:100) at $4^{\circ} \mathrm{C}$ overnight, followed by biotin-labelled goat anti-rat $\operatorname{IgG}$ and streptomycin anti-biotin peroxidase for $10 \mathrm{~min}$ at RT. Diaminobenzidine (DAB) was used as a chromogen. For the negative control, PBS was used instead of rat anti-mouse Foxp3 antibody.

Transfection of an expression plasmid encoding for mouse Foxp3. The mouse pcDNA3.1-Foxp3 plasmid was previously constructed in our laboratory. LLC cells were transfected with the mouse pcDNA3.1-Foxp3 plasmid or the pcDNA3.1 empty plasmid using FuGENE (Roche) according to the manufacturer's instructions. The expression of Foxp3 was detected by measuring the mRNA and protein levels after $48 \mathrm{~h}$.

RT-PCR analysis. Total cellular RNA was extracted with RNAiso $^{\text {TM }}$ Plus (Takara Bio, Inc., Shiga, Japan) according to the manufacturer's instructions. For reverse transcription, cDNA was generated using $1 \mu \mathrm{g}$ of total RNA, $2 \mu \mathrm{l}$ of oligo(dT) primers (Takara Bio,Inc.), $1 \mu 1$ of reverse transcriptase (M-MLV, Takara Bio, Inc.) and $1 \mu \mathrm{l}$ of dNTPs (10 mM) in a total volume of $20 \mu \mathrm{l}$.
For the PCR reactions, the primer sequences were as follows: Foxp3 sense, 5'-CAGCTGCCTACAGTGCCCCTAG-3' and antisense, 5'-CATTTGCCAGCAGTGGGTAG-3' (17); mdr1 sense, 5'-GGCATTGCCTACCTGTTGG-3' and antisense, 5'-GCTTTCTGTGGACACTTCTG-3' (18); and $\beta$-actin sense, 5'-TGGAATCCTGTGGCATCCATGAAAC-3' and antisense, 5'-TAAAACGCAGCTCAGTAACAGTCCG-3' (19). For Foxp3, the reaction conditions were as follows: $94^{\circ} \mathrm{C}$ for $30 \mathrm{sec}$, $60^{\circ} \mathrm{C}$ for $30 \mathrm{sec}$ and $72^{\circ} \mathrm{C}$ for $60 \mathrm{sec}$ for $35 \mathrm{cycles}$. For mdr1, the reaction conditions were as follows: $94^{\circ} \mathrm{C}$ for $30 \mathrm{sec}, 55^{\circ} \mathrm{C}$ for $30 \mathrm{sec}$ and $72^{\circ} \mathrm{C}$ for $90 \mathrm{sec}$ for 35 cycles. For $\beta$-actin, the reaction conditions were as follows: $94^{\circ} \mathrm{C}$ for $30 \mathrm{sec}, 52^{\circ} \mathrm{C}$ for $30 \mathrm{sec}$ and $72^{\circ} \mathrm{C}$ for $60 \mathrm{sec}$ for 25 cycles. All reactions were followed by an elongation step of $10 \mathrm{~min}$ at $72^{\circ} \mathrm{C}$. RT-PCR products were analysed by $1 \%$ agarose gel electrophoresis and stained by ethidium bromide. The ratio of Foxp3 or mdr1 to $\beta$-actin was calculated as the relative level of mRNA expression.

Western blot analysis. Nuclear proteins from LLC cells were extracted as described previously (20). Western blot analysis was performed as follows: 30-50 $\mu \mathrm{g}$ of total protein was separated by $10 \%$ SDS-polyacrylamide gel electrophoresis and then transferred onto PVDF membranes. The membranes were blocked with 5\% non-fat dry milk in phosphate-buffered saline plus $0.03 \%$ Tween-20 (PBST) at RT for $2 \mathrm{~h}$. Immunoblotting was performed using the rat anti-mouse Foxp3 monoclonal antibody (dilution, 1:200) in non-fat milk Tris-buffer at $4^{\circ} \mathrm{C}$ overnight. The membrane was then incubated with the goat anti-rat IgG/HRP (dilution, 1:2,000) for $2 \mathrm{~h}$ at RT. The rabbit anti-mouse $\beta$-actin antibody was used as an internal control. Protein expression was detected using BeyoECL Plus (Beyotime Biotech., Jiangsu, China).

Cell proliferation assay. To assess the chemosensitivity of LLC cells to various chemoreagents, the inhibitory rate of cell proliferation was determined by the MTT assay. pcDNA3.1-Foxp3-LLC, pcDNA3.1-LLC and LLC cells were plated in 96-well plates $\left(1 \times 10^{4}\right.$ cells/well) and cultured with $10 \% \mathrm{FBS}$ at $37^{\circ} \mathrm{C}$ and $5 \%$ $\mathrm{CO}_{2}$ overnight to allow cell attachment. The cells were then incubated with fresh DMEM containing various concentrations $(0,5,10,20$ or $40 \mu \mathrm{g} / \mathrm{ml})$ of ADM or MMC. Following $48 \mathrm{~h}$ of treatment, $20 \mu \mathrm{l} /$ well of MTT was added to the cells to reach a concentration of $0.5 \mathrm{mg} / \mathrm{ml}$. Following $4 \mathrm{~h}$ of reaction time, the supernatant was discarded and $200 \mu \mathrm{l}$ of DMSO (Gibco-BRL) was added. The optical density (OD) at $570 \mathrm{~nm}$ of each well was measured with the enzyme immunoassay instrument (Bio-Rad 2550, Bio-Rad, Hercules, CA, USA). Triplicate wells were used in each group. The $\mathrm{IC}_{50}$ was defined as the concentration of drug eliciting $50 \%$ cell death. Inhibitory rate $(\%)=[(\mathrm{OD}$ of control group - OD of treated group)/OD of control group] x100.

Flow cytometry for the expression of P-gp. Cells $(1,000,000)$ were collected and washed with PBS and then fixed with $4 \%$ paraformaldehyde $(1 \mathrm{ml} /$ tube $)$ for $20 \mathrm{~min}$ at $4^{\circ} \mathrm{C}$. The cells were centrifuged at $1,500 \mathrm{rpm}$ for $5 \mathrm{~min}$ and then incubated with $100 \mu \mathrm{l}$ of rabbit anti-mouse P-gp polyclonal antibody (dilution, 1:100) for $40 \mathrm{~min}$ at $4^{\circ} \mathrm{C}$. Following the incubation, the cells were washed with PBS and incubated with $100 \mu 1$ of FITC-conjugated goat anti-rabbit IgG (dilution, 1:100) for $30 \mathrm{~min}$ at $4^{\circ} \mathrm{C}$ in the dark. Following the incubation, the cells 
A

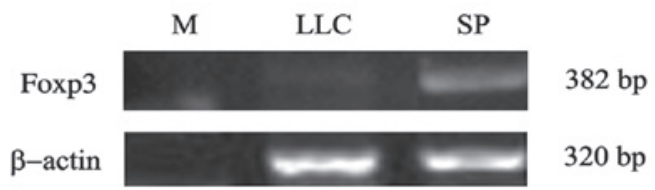

B
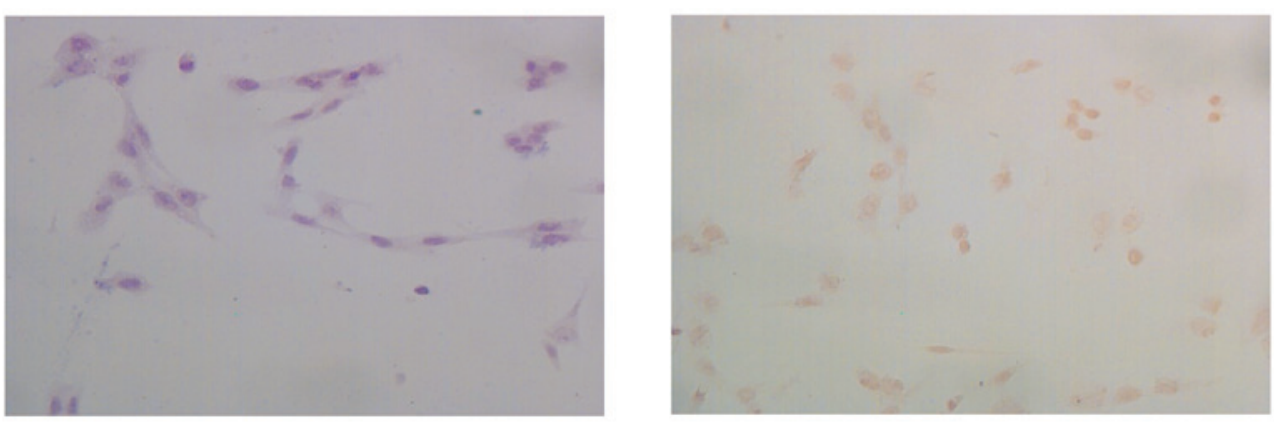

Figure 1. Expression of Foxp3 in LLC cells. (A) RT-PCR detection of Foxp3 mRNA expression in LLC cells. (B) Immunocytochemistry of LLC cells showing Foxp3 expression and localisation. Cells were incubated with PBS as the negative control (left panel) or rat anti-mouse Foxp3 antibody (right panel). The positive expression of Foxp3 protein is shown in LLC cells. Foxp3 protein was localised in the nucleus of LLC cells. Foxp3, forkhead box P3; LLC, Lewis lung cancer; M, DNA molecular marker; SP, mouse spleen cells. SP works as the positive control. .

A
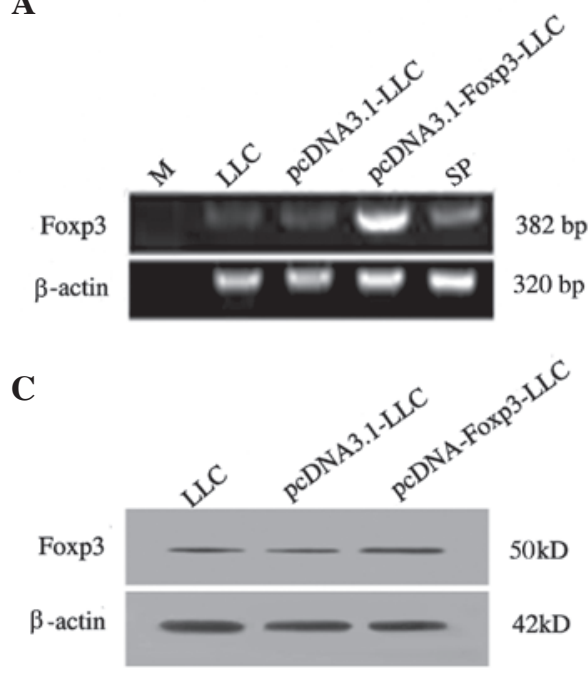

B
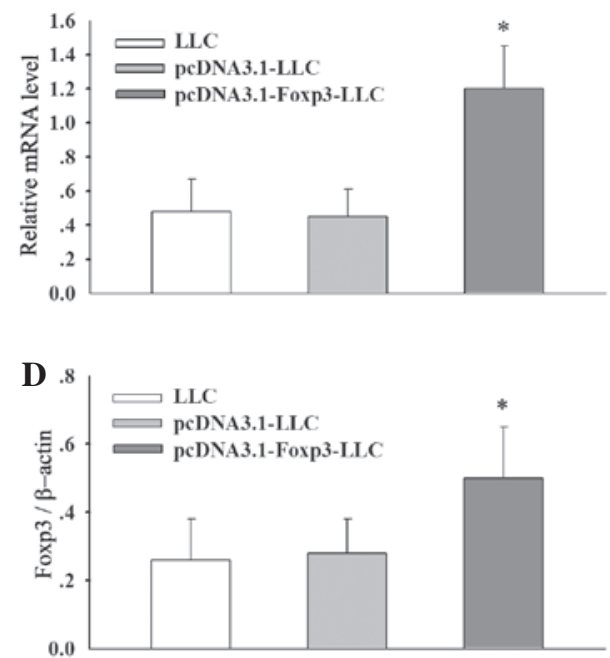

Figure 2. Expression of Foxp3 mRNA and protein in LLC cells transfected with Foxp3. (A) The levels of Foxp3 mRNA were detected by RT-PCR in LLC, pcDNA3.1-LLC and pcDNA3.1-Foxp3-LLC cells. (B) Graph of Foxp3 mRNA expression. The expression of Foxp3 mRNA in the pcDNA3.1-Foxp3-LLC group was significantly increased compared with that in the LLC and pcDNA3.1-LLC groups $(\mathrm{P}<0.01)$. (C) The levels of Foxp3 protein were detected by western blot analysis in LLC, pcDNA3.1-LLC and pcDNA3.1- Foxp3-LLC cells. (D) Graph of Foxp3 protein expression. The expression of Foxp3 protein in the pcDNA3.1-Foxp3-LLC group was significantly increased compared with that in the LLC and pcDNA3.1-LLC groups $(\mathrm{P}<0.01)$. " $\mathrm{P}<0.01$ vs. LLC group and pcDNA3.1-LLC group. Data are presented as the mean values of experiments performed in triplicate. Foxp3, forkhead box P3; LLC, Lewis lung cancer; M, DNA molecular marker; SP, mouse spleen cells. SP works as the positive control.

were washed with PBS and fixed in $4 \%$ paraformaldehyde $(0.5 \mathrm{ml} /$ tube) prior to detection by flow cytometry.

Statistical analysis. Statistical analysis was conducted using SPSS 12.0 software. All results are presented as the mean \pm SD. The Student's t-test was used for statistical analysis. $\mathrm{P}<0.05$ was considered the threshold for statistical significance.

\section{Results}

Foxp3 expression in LLC cells. The expression of Foxp3 mRNA was examined in mouse LLC cell lines by RT-PCR. The results revealed that Foxp3 was expressed in LLC cells
(Fig. 1A). The protein expression of Foxp3 was also confirmed by immunocytochemistry. Foxp3 protein was localised in the nucleus of LLC cells, as shown in Fig. 1B.

Establishment of Foxp3-overexpressing LLC cells. pcDNA3.1-Foxp3 recombinant or pcDNA3.1 empty plasmids were transiently transfected into LLC cells. The overexpression of Foxp3 in pcDNA3.1-Foxp3-LLC was confirmed by RT-PCR and western blot analysis. The results revealed that the expression of Foxp3 mRNA in the pcDNA3.1-Foxp3-LLC group was significantly increased compared with that of the LLC and pcDNA3.1-LLC groups ( $\mathrm{P}<0.01$; Fig. $2 \mathrm{~A}$ and $\mathrm{B})$. Western blot analysis also confirmed that the protein level of Foxp3 was 
A

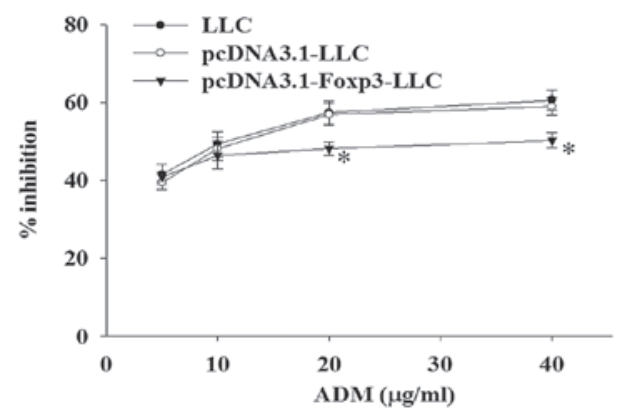

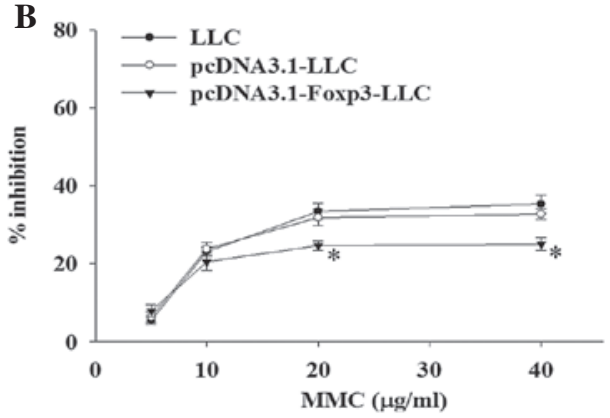

Figure 3. Effect of Foxp3 on proliferation inhibition of LLC cells following treatment with ADM and MMC by the MTT assay. (A) Proliferation inhibitory curve of LLC, pcDNA3.1-LLC and pcDNA3.1-Foxp3-LLC cells following treatment with ADM. The cells were incubated with various concentrations $(5-40 \mu \mathrm{g} / \mathrm{ml})$ of ADM for $48 \mathrm{~h}$. The inhibitory rate of cell proliferation in pcDNA3.1-Foxp3-LLC cells was significantly decreased after ADM treatment at 20 and $40 \mu \mathrm{g} / \mathrm{ml}(\mathrm{P}<0.05)$. (B) Proliferation inhibitory curve of LLC, pcDNA3.1-LLC and pcDNA3.1-Foxp3-LLC cells after treatment with MMC. The cells were incubated with various concentrations $(5-40 \mu \mathrm{g} / \mathrm{ml})$ of MMC for $48 \mathrm{~h}$. The inhibitory rate of cell proliferation in pcDNA3.1-Foxp3-LLC cells was significantly decreased after MMC treatment at 20 and $40 \mu \mathrm{g} / \mathrm{ml}(\mathrm{P}<0.05)$. ${ }^{*} \mathrm{P}<0.05 \mathrm{vs}$. LLC group and pcDNA3.1-LLC group. Data are presented as the mean values of experiments performed in triplicate. Foxp3, forkhead box P3; LLC, Lewis lung cancer; ADM, adriamycin; MMC, mitomycin C.

A

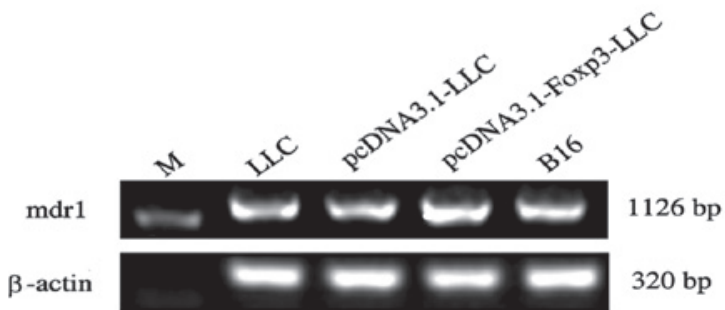

C
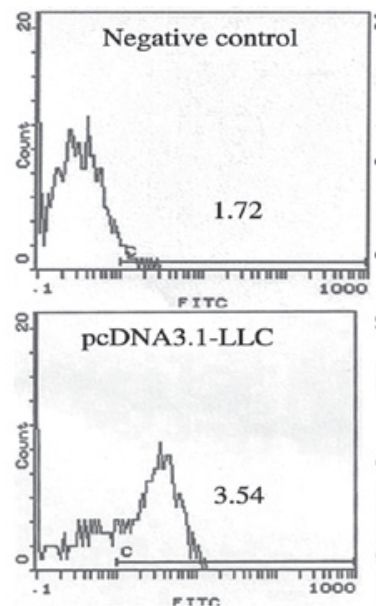
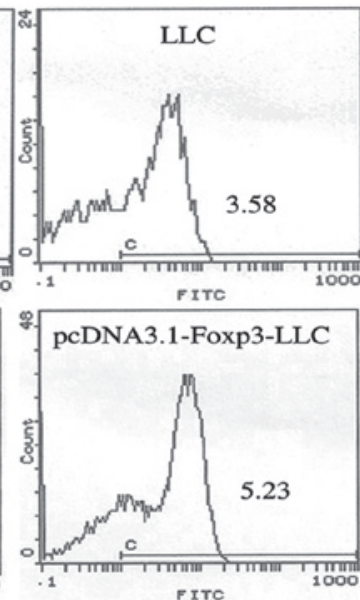

B

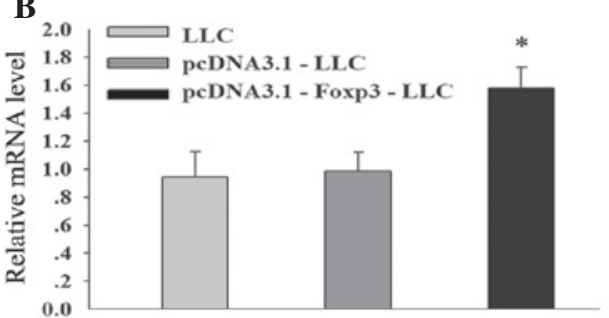

D

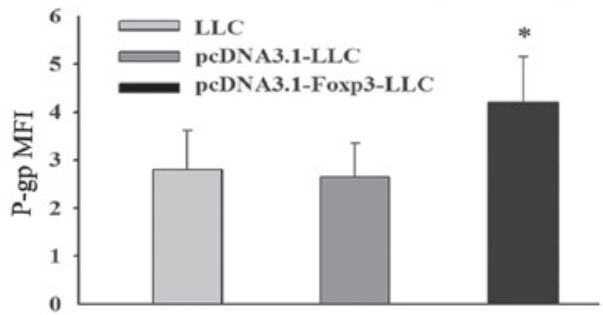

Figure 4. Expression of mdr1 mRNA and P-gp protein in LLC, pcDNA3.1-LLC and pcDNA3.1- Foxp3-LLC cells. (A) The levels of mdr1 mRNA were detected by RT-PCR in LLC, pcDNA3.1-LLC and pcDNA3.1-Foxp3-LLC cells. (B) Graph of mdr1 mRNA expression. The expression of mdr1 mRNA was significantly increased in the pcDNA3.1-Foxp3-LLC group when compared with the pcDNA3.1-LLC and LLC groups (P<0.05). (C) The levels of P-gp protein were detected by flow cytometry in LLC, pcDNA3.1-LLC and pcDNA3.1-Foxp3-LLC cells. (D) Graph of P-gp protein expression. The expression of P-gp protein was significantly increased in the pcDNA3.1-Foxp3-LLC group compared with the pcDNA3.1-LLC and LLC groups (P<0.05). "P<0.05 vs. LLC and pcDNA3.1-LLC groups. Data are presented as the mean values of experiments performed in triplicate. Foxp3, forkhead box P3; LLC, Lewis lung cancer; M, DNA molecular marker; B16, positive control; MFI, mean fluorescence intensity.

significantly increased in the pcDNA3.1-Foxp3-LLC group compared with that of the LLC and pcDNA3.1-LLC groups $(\mathrm{P}<0.01$; Fig. 2C and D).

Sensitivity to ADM and MMC chemotherapy in Foxp3-overexpressing LLC cells. To determine the effects of Foxp3 overexpression in LLC on sensitivity to chemotherapeutic agents, pcDNA3.1-Foxp3-LLC, pcDNA3.1-LLC and LLC cells were treated with various concentrations of ADM and MMC.
The inhibitory rate of cell proliferation was measured by the MTT assay at $48 \mathrm{~h}$. As shown in Fig. 3A, the inhibitory rate of cell proliferation in the pcDNA3.1-Foxp3-LLC group was significantly lower than that of the pcDNA3.1-LLC and LLC groups following treatment with 20 and $40 \mu \mathrm{g} / \mathrm{ml}$ of ADM $(\mathrm{P}<0.05)$. The $\mathrm{IC}_{50}$ of ADM for the pcDNA3.1-Foxp3-LLC group $(32.78 \mu \mathrm{g} / \mathrm{ml})$ was higher than that of the pcDNA3.1-LLC group $(12.97 \mu \mathrm{g} / \mathrm{ml})$ and the LLC group $(11.27 \mu \mathrm{g} / \mathrm{ml})$. Similarly, after treatment with MMC at the concentrations of 20 and 
$40 \mu \mathrm{g} / \mathrm{ml}$, the pcDNA3.1-Foxp3-LLC group also exhibited a significantly lower growth inhibitory rate compared with the pcDNA3.1-LLC and LLC groups $\left(\mathrm{P}<0.05\right.$; Fig. 3B). The $\mathrm{IC}_{50}$ of MMC for the pcDNA3.1-Foxp3-LLC group $(162.1 \mu \mathrm{g} / \mathrm{ml})$ was markedly higher than that of the pcDNA3.1-LLC group $(63.7 \mu \mathrm{g} / \mathrm{ml})$ and the LLC group $(50.8 \mu \mathrm{g} / \mathrm{ml})$.

Expression of mdrl $m R N A$ and P-gp protein in Foxp3 overexpressing LLC cells. To investigate the mechanism of the Foxp3-induced reduction in sensitivity to chemotherapy in LLC cells, RT-PCR was first used to examine whether Foxp3 expression was associated with mdr1 gene expression. The results revealed that the expression of mdrl mRNA was significantly increased in the pcDNA3.1-Foxp3-LLC group but not in the pcDNA3.1-LLC and LLC groups $(\mathrm{P}<0.05$; Fig. 4A and $\mathrm{B})$. To further confirm the upregulation of mdr1 by Foxp3, the expression of P-gp, the protein product of the mdr1 gene, was examined by flow cytometry. Similarly, the expression of P-gp was also significantly increased in the pcDNA3.1-Foxp3-LLC group compared with the pcDNA3.1-LLC and LLC groups $(\mathrm{P}<0.05$; Fig. 4C and D).

\section{Discussion}

Chemotherapy is the main strategy used in the clinical treatment of patients with NSCLC. However, patients with NSCLC are often resistant to the chemotherapeutic agents. This sensitivity to chemotherapy is the most significant factor affecting the survival rate of patients with NSCLC.

Foxp3 has been identified as the master regulator of the development and function of Tregs $(2,3)$. Tregs have been reported to be associated with tumourigenesis and poor prognosis in various types of cancer (6-9). Previous studies have demonstrated the expression of Foxp3 not only in Tregs but also in tumour cells from patients with pancreatic and breast cancer and other types of tumour (10-14). Some of these studies have shown that the expression of Foxp3 within tumour cells is associated with tumour progression and poor prognosis. Hinz et al indicated that Foxp3 was expressed in the nucleus of pancreatic carcinoma cells and that it shared similar growth-suppressive effects with Tregs (10). Merlo et al indicated that Foxp3 expression in primary breast carcinoma tumour cells was associated with a risk of poor overall survival rate and that this risk was correlated with the increased intensity of Foxp3 immunostaining (12). These studies suggest that Foxp3 expression within tumour cells mimics the function of Tregs. The present study also demonstrates the expression of Foxp3 in LLC cells at the genetic and protein levels. Similar to Tregs, Foxp3 protein is located in the nucleus of LLC cells.

In addition, certain studies have revealed that Tregs may be resistant to conventional chemotherapy, thus improving tumour immune evasion $(15,16)$. Szczepanski et al reported that acute myelogenous leukaemia patients with lower circulating Treg frequencies have an improved response to the induction of chemotherapy. During the post-induction period however, the Treg frequency and suppressive activity remain elevated, even in complete remission, suggesting that Tregs are resistant to conventional chemotherapy (15). In addition, it has been reported that advanced stage gastrointestinal cancer patients present with increased levels of Tregs 3 weeks after chemotherapy, which correlated with a poor prognosis (16). However, the correlation between Foxp3 within tumour cells and sensitivity to chemotherapy remains unclear.

ADM and MMC are conventional chemotherapeutic agents that are used for the treatment of NSCLC. The current study used mouse LLC cells to investigate whether Foxp3 is involved in the resistance to chemotherapy. The results demonstrated that the inhibitory rate of cell proliferation in Foxp3-overexpressing cells was significantly reduced following treatment with ADM and MMC, suggesting that Foxp3-overexpressing LLC cells are resistant to cell death by $\mathrm{ADM}$ and MMC. In general, patients exhibit lower chemosensitivity to chemotherapeutic agents with higher $\mathrm{IC}_{50}$ values. In the current study, the $\mathrm{IC}_{50}$ values of $\mathrm{ADM}$ and $\mathrm{MMC}$ for Foxp3-overexpressing LLC cells were higher than those in the empty plasmid-transfected and untransfected LLC cells, indicating that Foxp3-overexpressing LLC cells are less sensitive to ADM and MMC. The results of this study suggest that Foxp3 expression in LLC cells reduces the sensitivity of LLC cells to ADM and MMC, resulting in reduced tumour cell death by ADM and MMC.

Multidrug resistance, particularly when mediated by P-gp, is the main cause of reduced chemosensitivity, which is a major factor in the failure of chemotherapy $(21,22)$. P-gp, encoded by the mdrl gene, is a $170-\mathrm{kDa}$ transmembrane glycoprotein and is an energy-dependent drug pump of ATP-binding cassette (ABC) transporters. P-gp pumps intracellular drugs outside the cell by ATP-dependent conformational changes, thus reducing the concentration of drugs within tumour cells $(23,24)$. In tumour patients, P-gp effluxes natural hydrophobic anticancer drugs, including alkaloids (vinblastine, vincristine), antitumour antibiotics (ADM and actinomycin D), paclitaxel and the alkylating agent, MMC (25-27). We found that ADM and MMC are substrates of P-gp and therefore the expression levels of mdr1 mRNA and P-gp protein were measured. The results demonstrated that mdr1 mRNA and P-gp protein were upregulated in Foxp3-overexpressing LLC cells, suggesting that Foxp3 upregulates the expression of P-gp, resulting in a lower sensitivity of the LLC cells to ADM and MMC.

This study demonstrates that Foxp3 may reduce the sensitivity of LLC cells to ADM and MMC by upregulating the expression of P-gp. Foxp3 may be the significant factor responsible for the insensitivity to chemotherapy in LLC cells. These results may provide a new mechanism of resistance to chemotherapy for NSCLC.

\section{Acknowledgements}

This study was supported by grants from the Department of Immunology in the Norman Bethune College of Medicine at Jilin University.

\section{References}

1. Jemal A, Siegel R, Ward E, Hao Y, Xu J, Murray T and Thun MJ: Cancer statistics. CA Cancer J Clin 58: 71-96, 2008.

2. Hori S, Nomura T and Sakaguchi S: Control of regulatory T cell development by the transcription factor Foxp3. Science 299: 1057-1061, 2003.

3. Fontenot JD, Rasmussen JP, Williams LM, Dooley JL, Farr AG and Rudensky AY: Regulatory T cell lineage specification by the forkhead transcription factor Foxp3. Immunity 22: 329-341, 2005. 
4. Woo EY, Yeh H, Chu CS, Schlienger K, Carroll RG, Riley JL, Kaiser LR and June CH: Cutting edge: regulatory T cells from lung patients directly inhibit autologous $\mathrm{T}$ cell proliferation. J Immunol 168: 4272-4276, 2002.

5. Schneider T, Kimpfler S, Warth A, Schnabel PA, Dienemann H, Schadendorf D, Hoffmann $\mathrm{H}$ and Umansky V: Foxp3 ${ }^{+}$regulatory $\mathrm{T}$ cells and killer cells distinctly infiltrate primary tumors and draining lymph nodes in pulmonary adenocarcinoma. J Thorac Oncol 6: 432-438, 2011.

6. Shimizu K, Nakata M, Hirami Y, Yukawa T, Maeda A and Tanemoto K: Tumor-infiltrating Foxp3 ${ }^{+}$regulatory $\mathrm{T}$ cells are correlated with cyclooxygenase- 2 expression and are associated with recurrence in resected non-small cell lung cancer. J Thorac Oncol 5: 585-590, 2010.

7. Tokuno K, Hazama S, Yoshino S, Yoshida S and Oka M: Increased prevalence of regulatory T-cells in the peripheral blood of patients with gastrointestinal cancer. Anticancer Res 29: 1527-1532, 2009.

8. Deng L, Zhang H, Luan Y, Zhang J, Xing Q, Dong S, Wu X, Liu $M$ and Wang S: Accumulation of foxp $3^{+}$T regulatory cells in draining lymph nodes correlates with disease progression and immune suppression in colorectal cancer patients. Clin Cancer Res 16: 4105-4112, 2010.

9. Petersen RP, Campa MJ, Sperlazza J, et al: Tumor infiltrating Foxp $3^{+}$regulatory T-cells are associated with recurrence in pathologic stage I NSCLC patients. Cancer 107: 2866-2872, 2006.

10. Hinz S, Pagerols-Raluy L, Oberg HH, et al: Foxp3 expression in pancreatic carcinoma cells as a novel mechanism of immune evasion in cancer. Cancer Res 67: 8344-8350, 2007.

11. Zuo T, Liu R, Zhang H, Chang X, Liu Y, Wang L, Zheng P and Liu Y: FOXP3 is a novel transcriptional repressor for the breast cancer oncogene SKP2. J Clin Invest 117: 3765-3773, 2007.

12. Merlo A, Casalini P, Carcangiu ML, Malventano C, Triulzi T, Mènard S, Tagliabue E and Balsari A: FOXP3 expression and overall survival in breast cancer. J Clin Oncol 27: 1746-1752, 2009.

13. Wang LH, Su L and Wang JT: Correlation between elevated FOXP3 expression and increased lymph node metastasis of gastric cancer. Chin Med J (Engl) 123: 3545-3549, 2010.

14. Wang G, Liu G, Liu Y, Li X and Su Z: FOXP3 expression in esophageal cancer cells is associated with poor prognosis in esophageal cancer. Hepatogastroenterology 59: Mar 2, 2012 (Epub ahead of print). doi: 10.5754/hge11961.

15. Szczepanski MJ, Szajnik M, Czystowska M, et al: Increased frequency and suppression by regulatory $\mathrm{T}$ cells in patients with acute myelogenous leukemia. Clin Cancer Res 15: 3325-3332, 2009.
16. Xu H, Mao Y, Dai Y, Wang Q and Zhang X: CD4 ${ }^{+} \mathrm{CD} 25^{+}$regulatory $\mathrm{T}$ cells in patients with advanced gastrointestinal cancer treated with chemotherapy. Onkologie 32: 246-252, 2009.

17. Ruan Q, Kameswaran V, Tone Y, Li L, Liou HC, Greene MI, Tone $\mathrm{M}$ and Chen $\mathrm{YH}$ : Development of Foxp3 ${ }^{+}$regulatory $\mathrm{T}$ cells is driven by A c-Rel enhanceosome. Immunity 31: 932-940, 2009.

18. Melaine N, Liénard MO, Dorval I, Le Goascogne C, Lejeune H and Jégou B: Multidrug resistance genes and p-glycoprotein in the testis of the rat, mouse, Guinea pig, and human. Biol Reprod 67: 1699-1707, 2002.

19. Simeone L, Straubinger M, Khan MA, Nalleweg N, Cheusova T and Hashemolhosseini S: Identification of Erbin interlinking MuSK and ErbB2 and its impact on acetylcholine receptor aggregation at the neuromuscular junction. J Neurosci 30: 6620-6634, 2010.

20. Shim GS, Manandhar S, Shin DH, Kim TH and Kwak MK: Acquisition of doxorubicin resistance in ovarian carcinoma cells accompanies activation of the NRF2 pathway. Free Radic Biol Med 47: 1619-1631, 2009.

21. Widmer N, Colombo S, Buclin T and Decosterd LA: Functional consequence of MDR1 expression on imatinib intracellular concentrations. Blood 102: 1142, 2003.

22. Aller SG, Yu J, Ward A, et al: Structure of P-glycoprotein reveals a molecular basis for poly-specific drug binding. Science 323: 1718-1722, 2009.

23. Loo TW and Clarke DM: Location of the rhodamine-binding site in the human multidrug resistance P-glycoprotein. J Biol Chem 277: 44332-44338, 2002.

24. Ambudkar SV, Kim IW and Sauna ZE: The power of the pump: mechanisms of action of P-glycoprotein (ABCB1). Eur J Pharm Sci 27: 392-400, 2006.

25. Szachowicz-Petelska B, Figaszewski Z and Lewandowski W: Mechanisms of transport across cell membranes of complexes contained in antitumour drugs. Int J Pharm 222: 169-182, 2001.

26. Pires MM, Emmert D, Hrycyna CA and Chmielewski J: Inhibition of P-glycoprotein-mediated paclitaxel resistance by reversibly linked quinine homodimers. Mol Pharmacol 75: 92-100, 2009.

27. Enokida H, Gotanda T, Oku S, et al: Reversal of P-glycoprotein mediated paclitaxel resistance by new synthetic isoprenoids in human bladder cancer cell line. Jpn J Cancer Res 93: 1037-1046, 2002. 